\title{
Article \\ Efficacy and Pharmacological Appropriateness of Cinnarizine and Dimenhydrinate in the Treatment of Vertigo and Related Symptoms
}

\author{
Fulvio Plescia ${ }^{1}(1)$, Pietro Salvago ${ }^{2}$, Francesco Dispenza ${ }^{3}$, Giuseppe Messina ${ }^{4,5}$ (D) Emanuele Cannizzaro ${ }^{1}$ (i) \\ and Francesco Martines ${ }^{2, *}$ \\ 1 Department of Health Promotion Sciences Maternal and Infantile Care, Internal Medicine and Medical \\ Specialities "Giuseppe D'Alessandro", University of Palermo, Via del Vespro 133, 90127 Palermo, Italy; \\ fulvio.plescia@unipa.it (F.P.); emanuele.cannizzaro@unipa.it (E.C.) \\ 2 Dipartimento di Biomedicina, Neuroscienze e Diagnostica Avanzata (BiND), Sezione di Audiologia, \\ Università Degli Studi di Palermo, Via del Vespro 129, 90127 Palermo, Italy; pietro.salvago01@unipa.it \\ 3 UOC Otorinolaringoiatria, A.O.U.P. "Paolo Giaccone", Via del Vespro 129, 90127 Palermo, Italy; \\ francesco.dispenza@gmail.com \\ 4 Department of Psychological, Pedagogical and Human Movement Sciences, University of Palermo, \\ Via Giovanni Pascoli 6, Palermo 90144, Italy; giuseppe.messina17@unipa.it \\ 5 PosturaLab Center, 90127 Palermo, Italy \\ * Correspondence: francesco.martines@unipa.it
}

check for updates

Citation: Plescia, F.; Salvago, P.; Dispenza, F.; Messina, G.; Cannizzaro, E.; Martines, F. Efficacy and Pharmacological Appropriateness of Cinnarizine and Dimenhydrinate in the Treatment of Vertigo and Related Symptoms. Int. J. Environ. Res. Public Health 2021, 18, 4787. https:// doi.org/10.3390/ijerph18094787

Academic Editor: David Nichols

Received: 19 March 2021

Accepted: 28 April 2021

Published: 30 April 2021

Publisher's Note: MDPI stays neutral with regard to jurisdictional claims in published maps and institutional affiliations.

Copyright: (c) 2021 by the authors. Licensee MDPI, Basel, Switzerland. This article is an open access article distributed under the terms and conditions of the Creative Commons Attribution (CC BY) license (https:/ / creativecommons.org/licenses/by/ $4.0 /)$.
Abstract: Vertigo is not itself a disease, but rather a symptom of various syndromes and disorders that jeopardize balance function, which is essential for daily activities. It is an abnormal sensation of motion that usually occurs in the absence of motion, or when a motion is sensed inaccurately. Due to the complexity of the etiopathogenesis of vertigo, many pharmacological treatments have been tested for efficacy on vertigo. Among these drugs, cinnarizine, usually given together with dimenhydrinate, appears to be the first-line pharmacotherapy for the management of vertigo and inner ear disorders. Based on these considerations, the present non-interventional study aimed to investigate the clinical efficacy and tolerability of a fixed combination of cinnarizine $(20 \mathrm{mg})$ and dimenhydrinate $(40 \mathrm{mg})$ in patients suffering from vertigo-related symptoms. To this end, we enrolled 120 adults-70 males, and 50 females-with an average age of 64 years. Before beginning pharmacological treatment, all patients were screened for the intensity of vertigo, dizziness, and concomitant symptoms through the Visual Scale of Dizziness Disorders and Dizziness Handicap Inventory scales. At the end of the anamnestic evaluation, patients received the fixed-dose combination of cinnarizine (20 mg) plus dimenhydrinate $(40 \mathrm{mg}) 3$ times daily, for 60 days. The results of this study provide further insight regarding the efficacy of the fixed combination when used to reduce symptoms of vestibular vertigo of central and/or peripheral origin, after both the 15- and 60-day therapies. Independent of the type of vertigo, the fixed combination was able to reduce dizziness- and vertigo-associated symptoms in more than $75 \%$ of all patients treated, starting from 15 days of therapy, and improving 60 days after starting the therapy. Interestingly, we also found differences between male and female patients in the framework of the pharmacological effects of therapy. This study provides further details concerning the therapeutic efficacy of the fixed combination of cinnarizine and dimenhydrinate, and also focuses attention on the possibility that these drugs could act in a gender-specific manner, paving the way for further research.

Keywords: cinnarizine; dimenhydrinate; vertigo; dizziness; pharmacological treatment of vertigo

\section{Introduction}

Vertigo is not itself a disease, but rather a symptom of various syndromes and disorders that compromise balance function, which is essential for daily activities. Dizziness, vertigo, and disequilibrium may be due to complex modifications in central and peripheral 
neural activity [1]. In particular, an impairment of the vestibular system usually results from an alteration of the release of neurotransmitters and neuromodulators, which in turn affects the processing of sensory information [2-7].

Various studies have reported that vertigo is the most common complaint in patients of all ages, with a higher prevalence in adults over 60 years of age, and that about $15-20 \%$ of adults experience vertigo and dizziness yearly [8-10]. Furthermore, the prevalence rate of diseases increases with age, resulting in a steady rise in incidence due to the global rise in general life expectancy [11-13].

The maintenance of equilibrium is finely regulated by the brain, which tunes all the sensorial stimuli provided by the vestibular, visual, and proprioceptive systems, as well as the cognitive system [14-17]. Sensory inputs are further integrated and modulated by the extrapyramidal system, limbic system, and cerebral cortex [18].

The vestibular system is complex, and is usually divided into peripheral (the inner ear and the vestibular portion of the eighth cranial nerve) and central (vestibular nuclei, the oculomotor nuclei, the vestibulo-ocular reflex tracts, the cerebellum, the brainstem reticular formation, the area postrema, and other components) compartments $[19,20]$. Acute damage to the vestibular system promotes the genesis of different symptoms associated with vertigo, such as postural imbalance, nausea, vomiting, sensorineural hearing loss, migraine, and tinnitus $[16,17,21-25]$. Based on these considerations, it is evident that vertigo is a highly disabling disorder that negatively affects the ability to cope with daily activities, especially in elderly patients.

Because injury or neurodegenerative processes are responsible for damage to the vestibular system, understanding the etiopathogenesis of vestibular disease might be difficult. Therefore, this disorder requires an accurate diagnosis, including a detailed neuro-otological examination, in order to plan an adequate clinical intervention and/or a specific pharmacological strategy [26-28].

The first approach to a patient with vertigo may involve the use of pharmacological agents during the early acute phase of symptom onset, in order to provide fast relief. The goal of drug treatment is to suppress vestibular sensory input. This is thought to reduce conflicting sensory inputs, control undesirable perception, and improve the quality of the patient's life [29-31].

Due to the complexity of the etiopathogenesis of vertigo, many pharmacological treatments are targeted to control the activity of neurotransmitters, neuromodulators, and voltage-gated channels that play a pivotal role in the modulation of neuronal excitability. In particular, drugs from several broad categories have been tested for efficacy on vertigo, including calcium channel antagonists, antihistamines, diuretics, corticosteroids, antipsychotics, and other psychotherapeutic drugs [32-37]. These drugs have different mechanisms of action. They may reduce the strength of symptoms (e.g., vestibular suppressants) or modify the underlying disease processes that have led to the development of symptoms (e.g., calcium channel antagonists in the case of vestibular migraine). Moreover, many of these drugs, especially those with sedative effects, also have the ability to restore balance to patients with vestibular damage [38].

Among all of these drugs, cinnarizine appears to be the first-line pharmacotherapy for the management of vertigo and inner ear disorders. It may act on the peripheral vestibular system, blocking voltage-gated calcium channels, preventing calcium translocations across the vestibular air cells and, thus, regulating hair cell afferent vestibular transmission [39-41]. Through these actions, it promotes anti-vasoconstrictor activity and a reduction in the blood viscosity of the inner ear's circulatory system [42]. Cinnarizine has been used in clinical research at different doses, from $15 \mathrm{mg}$ thrice-daily to $150 \mathrm{mg} /$ day; however, its recommended clinical dose for the treatment of different vestibular disorders varies between $25 \mathrm{mg}$ thrice-daily and $75 \mathrm{mg}$ once-daily, up to a maximum of $225 \mathrm{mg}$ [43,44]. Today, cinnarizine is usually given together with dimenhydrinate, a drug that exerts anti-vertigo and anti-emetic effects, acting as histamine (H1) receptor antagonist and phosphodiesterase inhibitor in the vestibular nuclei and the vomiting center [45]. 
Considering the limited publications in the last two decades about the pharmacological activity of cinnarizine plus dimenhydrinate in the treatment of vertigo, the present noninterventional study aimed to investigate the clinical efficacy and tolerability of a fixed combination of cinnarizine $(20 \mathrm{mg})$ and dimenhydrinate $(40 \mathrm{mg})$ in patients suffering from vertigo-related symptoms.

\section{Patients, Materials and Methods}

This prospective, open-label, non-interventional study was conducted from June 2020 to December 2020. The study enrolled 120 adults -70 males and 50 females $(\mathrm{M} / \mathrm{F}$ ratio $=1.4)$ (mean age: 64 years); the female patients were on average slightly older than the male patients (Table 1). The recruited patients came from light work environments such as office employment, senior executives, and other work without exposure to noise.

Table 1. Demographic data and other baseline characteristic of patients included in the study.

\begin{tabular}{cccccccc}
\hline Parameters & \multicolumn{2}{c}{ Patients } & \multicolumn{5}{c}{ Statistical Data } \\
& Na & \% & Mean & SD & & Range \\
& & & & & Min & Med & Max \\
\hline Age (years) & & & 64.425 & 9.03 & 43 & 64 & 81 \\
Male & 70 & $55 \%$ & 64.9 & 7.77 & 46 & 64 & 79 \\
Female & 50 & $45 \%$ & 63.8 & 10.71 & 41 & 65 & 81 \\
Height (cm) & & & 1.61 & 0.08 & 1.45 & 1.6 & 1.75 \\
Weight (kg) & & & 71.49 & 12.1 & 42 & 72 & 95 \\
BMI (Kg/m2) & & & 26.45 & 3.71 & 17 & 26 & 31 \\
Duration of Vertigo & & & & 2.29 & 5 & 8 & 14 \\
(month) & & & & & & & \\
\hline
\end{tabular}

Na: Number; \%: percentage of patients; Mean: mean value; SD: standard deviation; Range Min, Med, and Max, respectively: minimum, median and maximum.

Almost one third of the patients had taken antivertigo drugs before being included in the study, and it can be assumed that, in most cases, the previous medical treatment had been discontinued due to poor efficacy, and was replaced by the combined preparation.

On the first visit, all patients underwent a careful medical history collection, which included differential diagnosis, duration of vertigo, prior medical treatment, concurrent disease—-such as hearing loss, tinnitus, and/or headache—and concomitant medications. Each subject underwent a careful otological examination using micro-otoscopy in order to rule out external/middle ear disease. A bedside examination-including tests for spontaneous nystagmus, smooth pursuit, and saccade, as well as the head shaking test and the Romberg test-was performed. In addition, a detailed neurological examination, including assessment of the cranial nerve and cerebellar functions, manual muscle testing for power, and somatosensory assessments, was also performed.

Exclusion criteria were: aged younger than 18 years, history of acute unilateral vestibulopathy, benign paroxysmal positional vertigo (BPPV), vestibular migraine, definite Ménière's disease, MRI-documented retrocochlear disease (e.g., schwannoma), and exposure to ototoxic drugs.

The intensity of vertigo and concomitant symptoms were assessed by the Visual Scale of Dizziness Disorders, a five-point verbal rating (or visual analogue) scale ranging from no vertigo (0) to rarely (1), occasionally (2), frequently (3), and continuously (4). The following symptoms and triggering factors were investigated: instability, staggering, tendency to fall, swaying, position, inclination, walking, getting up, and head movements.

To value the perceived severity of dizziness, its impact on life, and the effectiveness of therapy, all patients were invited to complete the Dizziness Handicap Inventory (DHI). This tool is a 25-item survey with a total score ranging between 0 and 100 points, divided into three subscales: the functional subscale ( 36 points), the emotional subscale (36 points), and the physical subscale (28 points). Each item has 3 potential answers, with "yes" assigned 4 points, "sometimes" 2 points, and "no" 0 points. 
These parameters have been evaluated at the beginning of treatment (T0), 15 days after the treatment (T15), and at the end of the observational period (T60) (Figure 1). We chose a period of 60 days for the final evaluation of the drugs' effects, because this is a useful period for vestibular restoration. At the end of the anamnestic evaluation, patients received the fixed-dose combination of cinnarizine $(20 \mathrm{mg})$ plus dimenhydrinate $(40 \mathrm{mg})$, 3 times daily for 60 days.

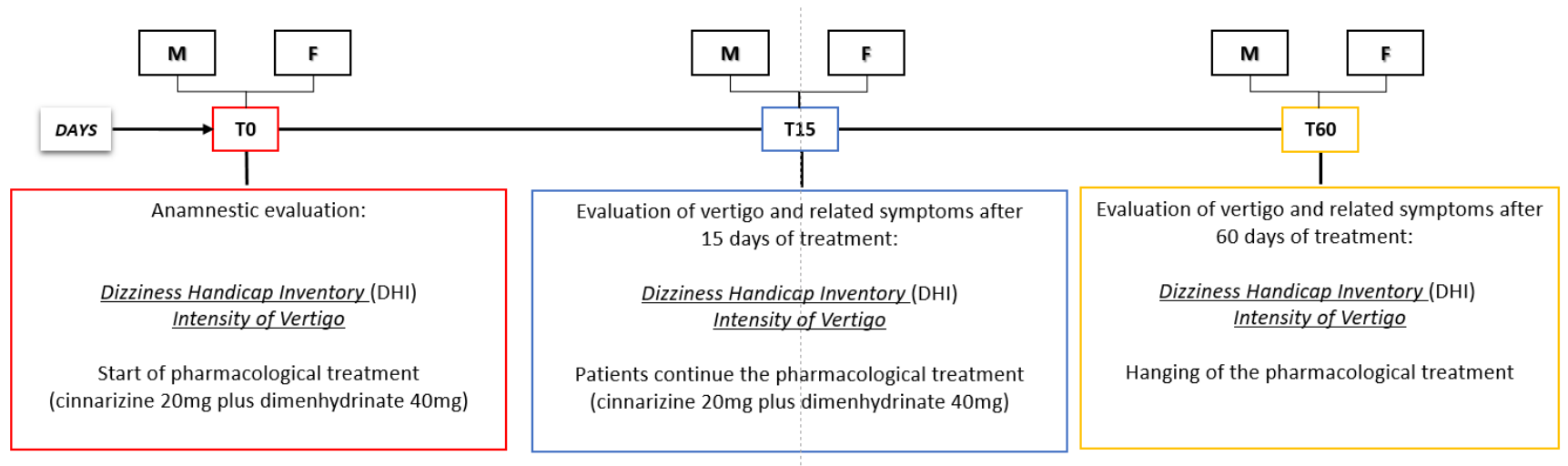

Figure 1. Timeline of the experimental procedures. M: male; F: female; T0: time at which the pharmacological treatment started; T15: 15 days after the beginning of the pharmacological treatment; T60: end of the treatment.

\section{Statistical Analysis}

Statistical analysis was performed using the GraphPad Prism 8.01 statistical software package (GraphPad Company, San Diego, CA, USA). Data were tested for normal distribution using the Kolmogorov-Smirnov test. Because of their normal distribution, the statistical analysis was performed using a parametric test, as reported.

Data obtained on the reduction of dizziness and vertigo symptoms were analyzed using a one-way ANOVA, followed by a post-hoc Tukey's multiple comparison test. With regard to the data on the assessments of the vertiginous disorder, a two-way ANOVA was used, followed by a post-hoc Bonferroni test with ordinary alpha $=0.5$. Data are reported as mean $\pm \mathrm{SD}$. Statistical significance was set at $p<0.05$.

\section{Results}

\subsection{Dizziness Handicap Inventory (DHI)}

The assessment of the effectiveness of pharmacological treatment on dizziness was conducted at three different points in time. In particular, statistical analysis conducted using a one-way ANOVA of the repeated measures performed to treat dizziness showed a significant effect of the treatment on all patients studied $(\mathrm{F}(2.119)=154.6 ; p<0.0001)$. When the data were analyzed so as to understand the time at which pharmacological treatment was most effective, a post-hoc Tukey's multiple comparison test showed a significant reduction in dizziness symptoms at T60, when compared to T15 and T0 $(q=15.51 p<0.001$; $q=24.59 p<0.001)$ and at T15 with respect to T0 $(q=9.082 p<0.001)$ (Figure 2$)$.

Furthermore, in order to evaluate whether pharmacological treatment was effective in both male and female patients, we also performed a statistical analysis by gender. A one-way ANOVA of the repeated measures performed to treat dizziness showed significant effects of the treatment on both male $(\mathrm{F}(2.69)=21.81 ; p<0.0001)$ and female $(\mathrm{F}(2.49)=9.915$; $p<0.0001)$ patients. Data from a post-hoc Tukey's multiple comparison test showed a significant reduction in dizziness symptoms at T60, compared to to T15 and T0, in both male $(q=12.33 p<0.001 ; q=18.33 p<0.001)$ and female $(q=10.48 p<0.001 ; q=17.97 p<0.001)$ patients. We also found a significant reduction in dizziness symptoms from T15 onwards in both male $(q=5.677 p<0.001)$ and female $(q=7.491 p<0.001)$ patients (Figure 3A,B). 


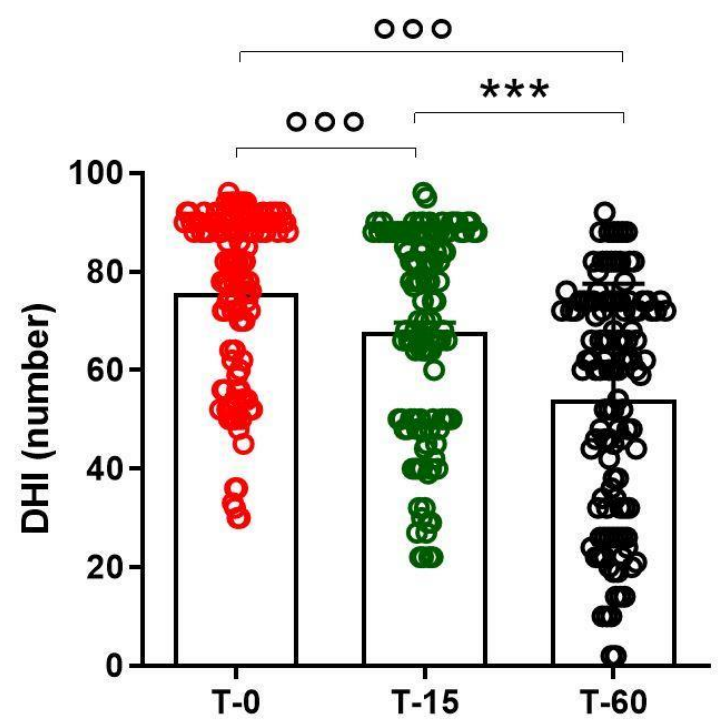

Figure 2. Reduction of dizziness symptoms, evaluated using the Dizziness Handicap Inventory (DHI), assessed at different times after pharmacological treatment with a fixed-combination preparation of cinnarizine $(20 \mathrm{mg})$ plus dimenhydrinate $(40 \mathrm{mg})$. Data refer to $n=120$ patients, and are represented as the mean $\pm \mathrm{SD}$ of DHI symptoms. ${ }^{* * *} p<0.001$ vs. T15; ${ }^{\circ 00} p<0.001$ vs. T0. T0: baseline; T15: evaluation after 15 days from the start of therapy; T60: evaluation at the end of therapy.
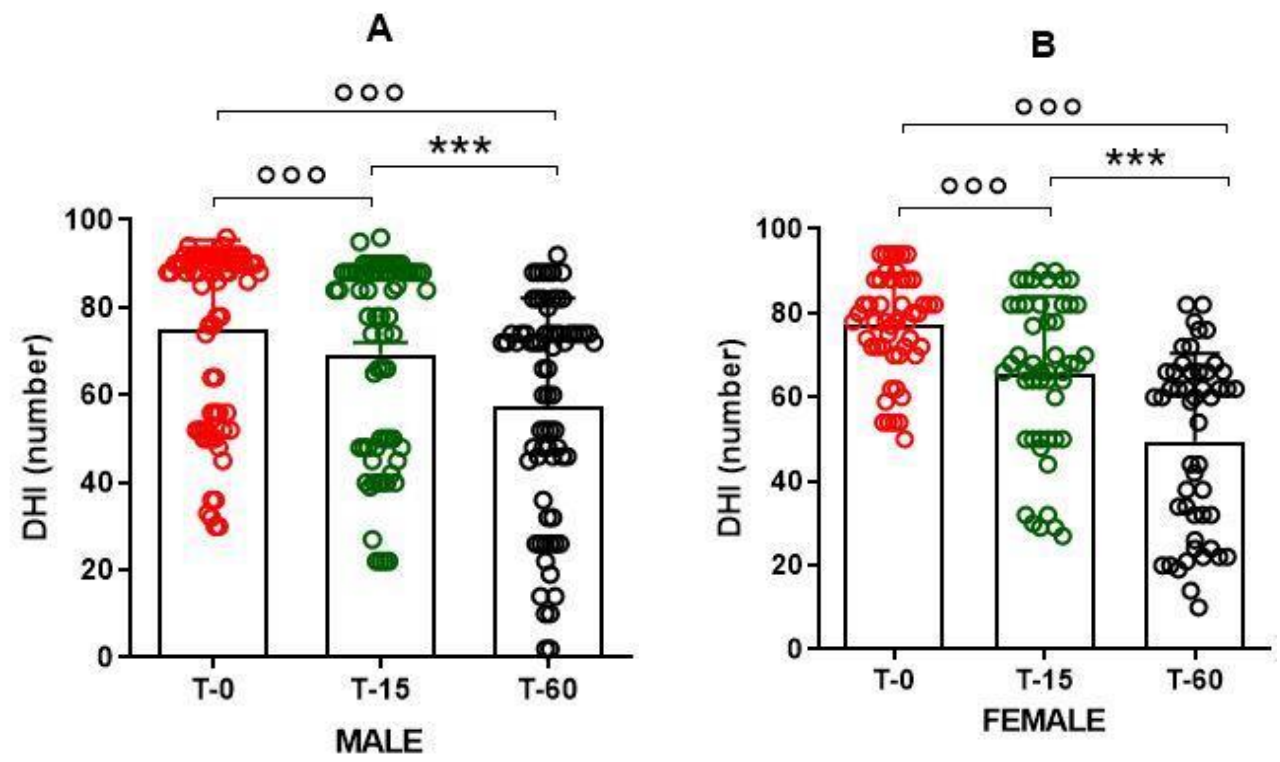

Figure 3. Reduction of dizziness symptoms, evaluated using the Dizziness Handicap Inventory (DHI), assessed at different times after pharmacological treatment with a fixed-combination preparation of cinnarizine (20 $\mathrm{mg})$ plus dimenhydrinate $(40 \mathrm{mg})$. Data refer to $(\mathbf{A}) n=70$ male, and $(\mathbf{B}) n=50$ female patients, and are represented as the mean \pm SD of DHI symptoms. ${ }^{* * *} p<0.001$ vs. T15; ${ }^{\circ 00} p<0.001$ vs. T0. T0: baseline; T15: evaluation after 15 days from the start of therapy; T60: evaluation at the end of therapy.

\subsection{Vertigo Symptoms \\ 4.2.1. All Patients}

Statistical analysis, performed based on the observations of the parameters obtained through the use of the Visual Scale of Dizziness Disorders on vegetative symptoms, highlighted a significant time effect of pharmacological treatment on the reduction of dizziness symptoms. A two-way ANOVA showed a significant effect of pharmacological treatment on time $(\mathrm{F}(2,14)=447.22, p<0.0001)$, symptoms $(\mathrm{F}(7,14)=8.421, p<0.0001)$, and their 
interaction $(\mathrm{F}(2,7)=4.169, p<0.0001)$. A Bonferroni post-hoc analysis indicated that pharmacological treatment with a fixed-combination preparation of cinnarizine $(20 \mathrm{mg})$ plus dimenhydrinate $(40 \mathrm{mg})$ was able to reduce most of the symptoms related to the vertiginous disorder (Figure 4). In particular, a significant reduction in all analyzed symptoms was recorded 15 days after starting therapy (T15), compared to T0; furthermore, a reduction of instability was also detected between T0 and T60 (Table 2).

Rating of the dizziness

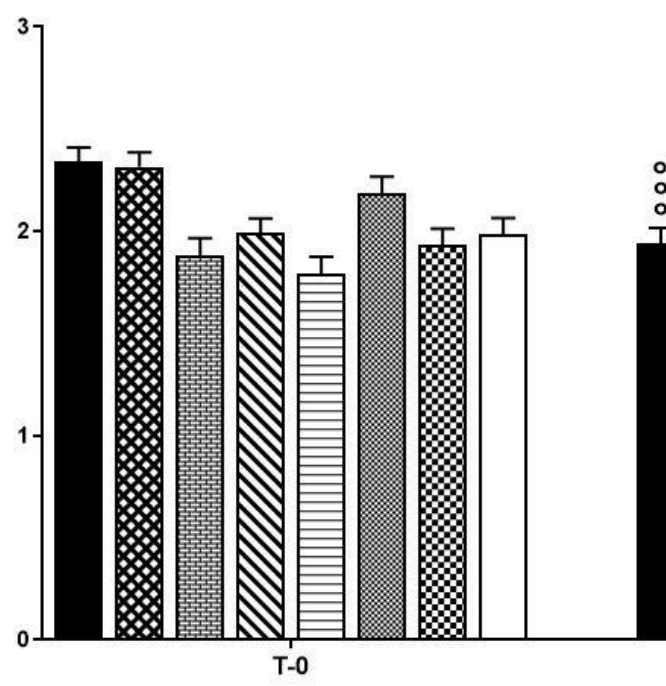

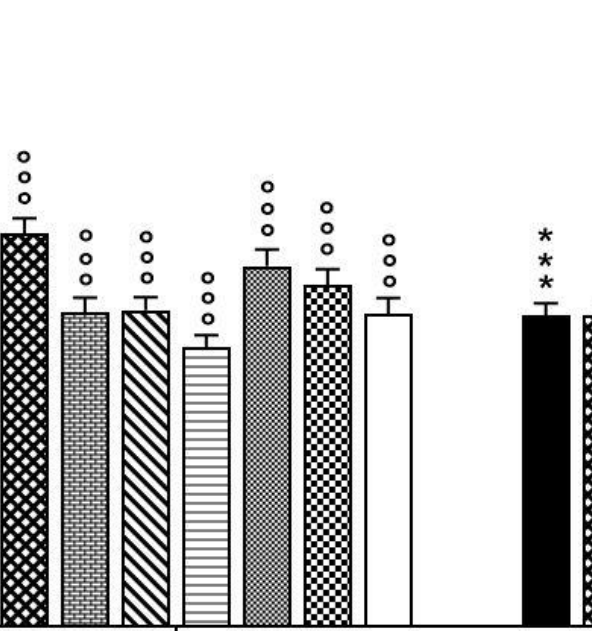

T-15

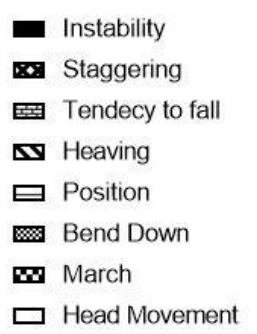

$\square$ Head Movement

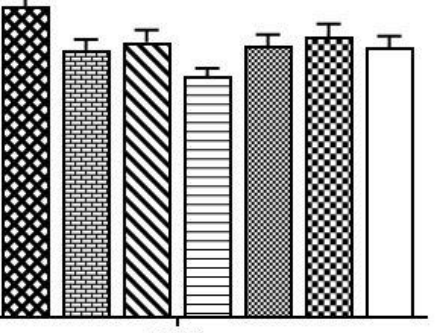

Figure 4. The intensity of vertigo and concomitant symptoms, as evaluated by the five-point verbal rating (or visual analogue) scale - ranging from no vertigo (0) to rarely (1), occasionally (2), frequently (3), and continuously (4) — has been taken into account in order to assess the efficacy of treatment with a fixed-combination preparation of cinnarizine (20 mg) plus dimenhydrinate $(40 \mathrm{mg})$ on the reduction of the triggering factors of the dizziness itself. Data refer to $n=120$ patients, and are represented as the mean $\pm \mathrm{SD}$ of the factors able to trigger vertigo. ${ }^{* * *} p<0.001 \mathrm{vs}$. T15; ${ }^{\circ 00} p<0.001 \mathrm{vs}$. T0. T0: baseline; T15: evaluation after 15 days from the start of therapy; T60: evaluation at the end of therapy.

\subsubsection{Male Patients}

When statistical analysis was performed on the male patients, a two-way ANOVA performed on the observations of the parameters obtained through the use of the Visual Scale of Dizziness Disorders on vegetative symptoms revealed a significant effect of pharmacological treatment on time $(\mathrm{F}(2,14)=110.23, p<0.0001)$, symptoms $(\mathrm{F}(7,14)=7.73$, $p<0.0001)$, and their interaction $(\mathrm{F}(2,7)=8.90, p<0.0001)$. A Bonferroni post-hoc analysis indicated that pharmacological treatment with a fixed-combination preparation of cinnarizine $(20 \mathrm{mg})$ plus dimenhydrinate $(40 \mathrm{mg})$ was able to reduce most of the symptoms related to the vertiginous disorder (Figure 5). In particular, a significant reduction in immobility, staggering, tendency to fall, bending down, and marching was recorded between T15 and T60, although a decrease in staggering and position was recorded at T15 compared to T0 (Table 3).

\subsubsection{Female Patients}

When the data obtained was analyzed only for female subjects, a statistical analysis conducted using a two-way ANOVA performed on the observations of the parameters obtained through the use of the Visual Scale of Dizziness Disorders on vegetative symptoms highlighted a significant effect of time $(\mathrm{F}(2,14)=375.1, p<0.0001)$, symptoms $(\mathrm{F}(7,14)=12.35, p<0.0001)$, and their interaction $(\mathrm{F}(2,7)=12.35, p<0.0001)$. In particular, a Bonferroni post-hoc analysis indicated that the pharmacological treatment with a fixedcombination preparation of cinnarizine $(20 \mathrm{mg})$ plus dimenhydrinate $(40 \mathrm{mg})$ was able 
to reduce the symptoms related to the vertiginous disorder (Figure 6). Interestingly, the reduction in all symptoms began after 15 days of therapy, and remained unchanged after 60 days of treatment (Table 4$)$.

Table 2. Statistical analysis obtained using a Bonferroni post-hoc test on the factors triggering the onset of vertigo.

\begin{tabular}{|c|c|c|c|c|}
\hline \multicolumn{5}{|l|}{ T0 Vs. T15 } \\
\hline Symptoms & Mean Difference & $t$ & $p$ Value & Summary \\
\hline Instability & 0.6100 & 6.801 & $p<0.001$ & 000 \\
\hline Staggering & 0.9510 & 10.60 & $p<0.001$ & ০০ \\
\hline Tendency to Fall & 0.8550 & 9.533 & $p<0.001$ & ০০০ \\
\hline Heaving & 0.4850 & 5.408 & $p<0.001$ & ০০ \\
\hline Position & 0.9500 & 10.59 & $p<0.001$ & ০০০ \\
\hline Bend Down & 0.5950 & 6.634 & $p<0.001$ & ০০০ \\
\hline March & 0.6350 & 7.080 & $p<0.001$ & $\circ \circ \circ$ \\
\hline Head Movement & 0.4900 & 5.463 & $p<0.001$ & ০০০ \\
\hline \multicolumn{5}{|l|}{ T15 Vs. T60 } \\
\hline Symptoms & Mean Difference & $t$ & $p$ Value & Summary \\
\hline Instability & 0.5050 & 5.631 & $p<0.001$ & $* * *$ \\
\hline Staggering & -0.1160 & 1.293 & $p>0.05$ & ns \\
\hline Tendency to Fall & 0.2200 & 2.453 & $p>0.05$ & ns \\
\hline Heaving & 0.1750 & 1.951 & $p>0.05$ & ns \\
\hline Position & 0.1900 & 2.118 & $p>0.05$ & ns \\
\hline Bend Down & 0.2350 & 2.620 & $p>0.05$ & ns \\
\hline March & 0.2650 & 2.955 & $p>0.05$ & ns \\
\hline Head Movement & 0.2050 & 2.286 & $p>0.05$ & ns \\
\hline
\end{tabular}

Data refer to $n=120$ patients. $* * * p<0.001$ vs. T15; ${ }^{\circ 00} p<0.001$ vs. T0. T0: baseline; T15: evaluation after 15 days from the start of therapy; T60: evaluation at the end of therapy.

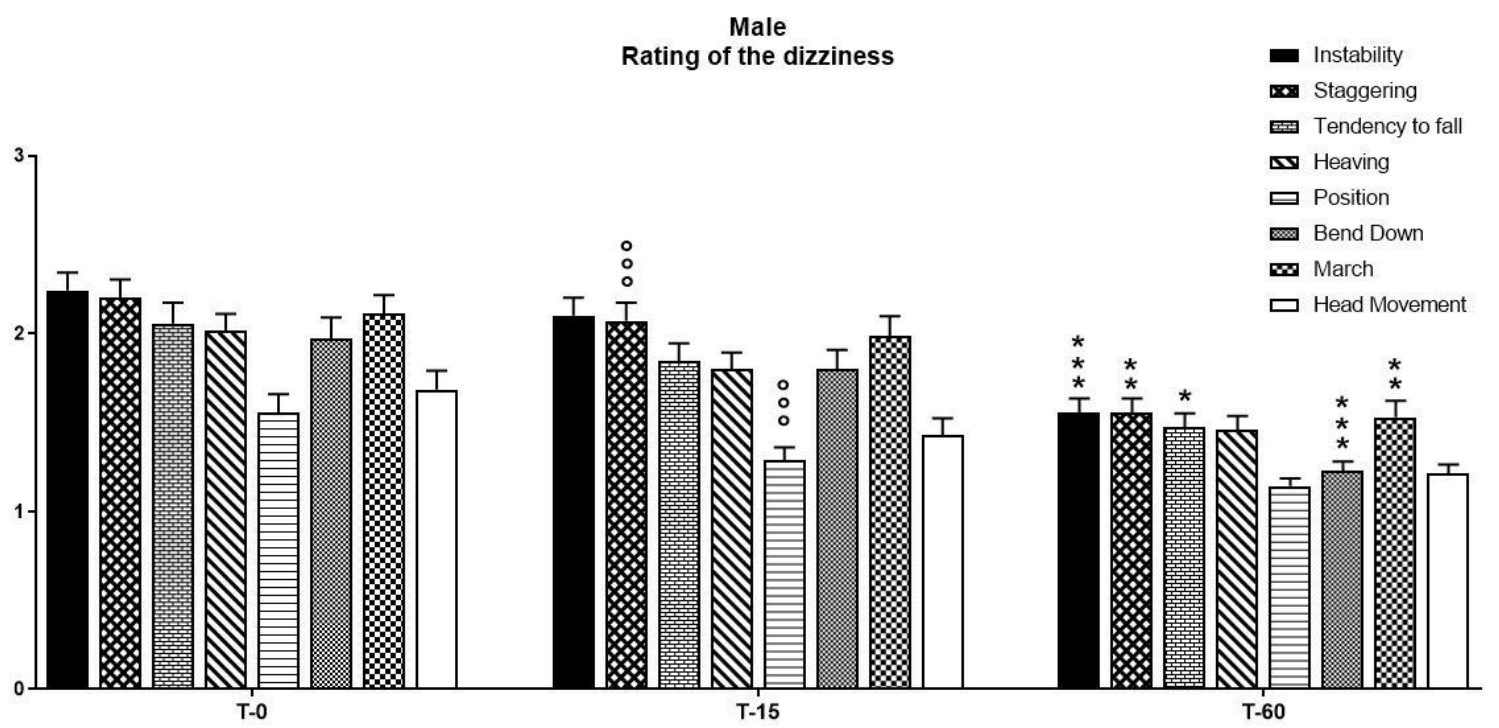

Figure 5. The intensity of vertigo and concomitant symptoms as evaluated by the five-point verbal rating (or visual analogue) scale-ranging from no vertigo (0) to rarely (1), occasionally (2), frequently (3), and continuously (4) - have been taken into account in order to assess the efficacy of treatment with a fixed-combination preparation of cinnarizine (20 mg) plus dimenhydrinate $(40 \mathrm{mg})$ on the reduction of the triggering factors of the dizziness itself. Data refer to $n=70$ male patients, and are represented as the mean \pm SD of the factors able to trigger vertigo. ${ }^{*} p<0.05,{ }^{* *} p<0.01,{ }^{* * *} p<0.001$ vs. T15; ${ }^{\circ 0} p<0.001$ vs. T0. T0: baseline; T15: evaluation after 15 days from the start of therapy; T60: evaluation at the end of therapy. 
Table 3. Statistical analysis obtained using a Bonferroni post-hoc test on the factors triggering the onset of vertigo.

\begin{tabular}{ccccc}
\hline T0 Vs. T15 & & & & \\
\hline Symptoms & Mean Difference & $t$ & $p$ Value & Summary \\
\hline Instability & -0.06000 & 0.4609 & $p>0.05$ & $\mathrm{~ns}$ \\
Staggering & 1.142 & 8.773 & $p<0.001$ & $\circ \circ \mathrm{n}^{-}$ \\
Tendency to Fall & 0.2300 & 1.767 & $p>0.05$ & $\mathrm{~ns}$ \\
Heaving & 0.2100 & 1.613 & $p>0.05$ & $\mathrm{~ns}$ \\
Position & 1.260 & 9.680 & $p<0.001$ & $\circ \circ$ \\
Bend Down & 0.1100 & 0.8451 & $p>0.05$ & $\mathrm{~ns}$ \\
March & 0.1100 & 0.8651 & $p>0.05$ & $\mathrm{~ns}$ \\
Head Movement & 0.2600 & 1.997 & $p>0.05$ & $\mathrm{~ns}$ \\
T15 Vs. T60 & & & & \\
Symptoms & Mean Difference & $t$ & $p$ Value & Summary \\
Instability & 0.5300 & 4.072 & $p<0.001$ & $* * *$ \\
Staggering & -0.4720 & 3.626 & $p<0.01$ & $* *$ \\
Tendency to Fall & 0.4200 & 3.227 & $p<0.05$ & $*$ \\
Heaving & 0.3500 & 2.689 & $p>0.05$ & $\mathrm{~ns}$ \\
Position & 0.1400 & 1.076 & $p>0.001$ & $\mathrm{~ns}$ \\
Bend Down & 0.5500 & 4.225 & $p<0.001$ & $* * *$ \\
March & 0.4400 & 3.380 & $p<0.01$ & $* *$ \\
Head Movement & 0.2100 & 1.613 & $p>0.05$ & $\mathrm{~ns}$ \\
\hline
\end{tabular}

Data refer to $\mathrm{n}=70$ male patients. ${ }^{*} p<0.05,{ }^{* *} p<0.01,{ }^{* * *} p<0.001$ vs. T15; ${ }^{\circ 00} p<0.001$ vs. T0. T0: baseline T15: evaluation after 15 days from the start of therapy; T60: evaluation at the end of therapy.

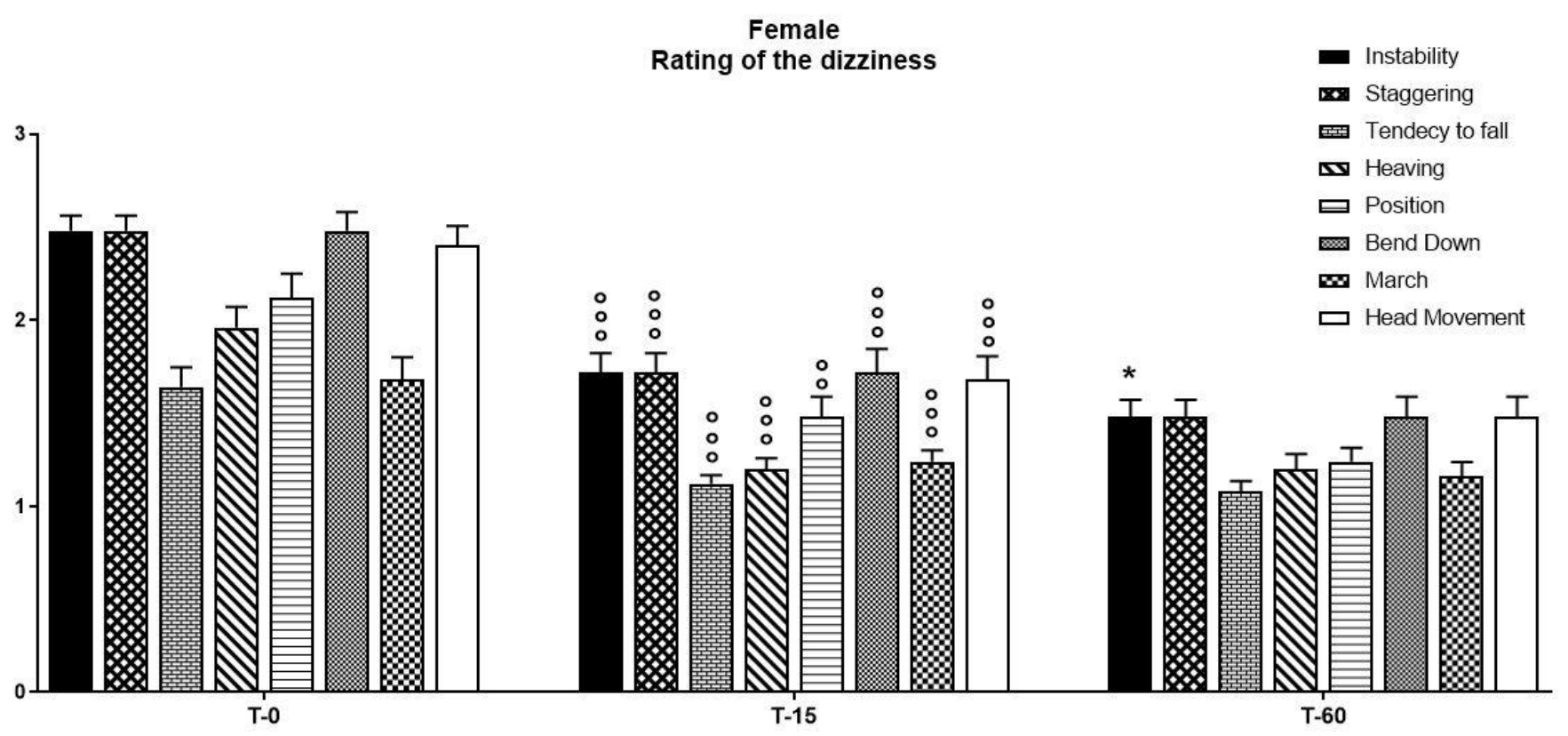

Figure 6. The intensity of vertigo and concomitant symptoms as evaluated by the five-point verbal rating (or visual analogue) scale — ranging from no vertigo (0) to rarely (1), occasionally (2), frequently (3), and continuously (4)—have been taken into account in order to assess the efficacy of treatment with a fixed-combination preparation of cinnarizine $(20 \mathrm{mg}$ ) plus dimenhydrinate $(40 \mathrm{mg})$ on the reduction of the triggering factors of the dizziness itself. Data refer to $n=50$ female patients, and are represented as the mean $\pm \mathrm{SD}$ of the factors able to trigger vertigo. ${ }^{*} p<0.05 \mathrm{vs} . \mathrm{T} 15 ;{ }^{\circ 0} p<0.001$, ${ }^{\circ 0 \circ} p<0.001$ vs. T0. T0: baseline; T15: evaluation after 15 days from the start of therapy; T60: evaluation at the end of therapy. 
Table 4. Statistical analysis obtained using a Bonferroni post-hoc test on the factors triggering the onset of vertigo.

\begin{tabular}{|c|c|c|c|c|}
\hline \multicolumn{5}{|l|}{ T0 Vs. T15 } \\
\hline Symptoms & Mean Difference & $t$ & $p$ Value & Summary \\
\hline Instability & 1.280 & 10.07 & $p<0.001$ & ০০০ \\
\hline Staggering & 0.760 & 5.977 & $p<0.001$ & ০०০ \\
\hline Tendency to Fall & 1.480 & 11.64 & $p<0.001$ & ০০ \\
\hline Heaving & 0.7600 & 5.977 & $p<0.001$ & ০০০ \\
\hline Position & 0.6400 & 5.033 & $p<0.01$ & $\circ \circ$ \\
\hline Bend Down & 1.080 & 8.493 & $p<0.001$ & ০০০ \\
\hline March & 1.160 & 9.122 & $p<0.001$ & ০০০ \\
\hline Head Movement & 0.7200 & 5.662 & $p<0.001$ & ০০০ \\
\hline \multicolumn{5}{|l|}{ T15 Vs. T60 } \\
\hline Symptoms & Mean Difference & $t$ & $p$ Value & Summary \\
\hline Instability & 0.4800 & 3.775 & $p<0.05$ & * \\
\hline Staggering & 0.2400 & 1.887 & $p>0.05$ & ns \\
\hline Tendency to Fall & 0.0200 & 0.1573 & $p>0.05$ & ns \\
\hline Heaving & 0.000 & 0.000 & $p>0.05$ & ns \\
\hline Position & 0.240 & 1.887 & $p>0.05$ & ns \\
\hline Bend Down & -0.08000 & 0.6291 & $p>0.05$ & ns \\
\hline March & 0.08000 & 0.6390 & $p>0.05$ & ns \\
\hline Head Movement & 0.2000 & 1.573 & $p>0.05$ & ns \\
\hline
\end{tabular}

Data refer to $\mathrm{n}=50$ female patients. ${ }^{*} p<0.05$ vs. T15; ${ }^{\circ 0} p<0.001,{ }^{\circ 00} p<0.001$ vs. T0. T0: baseline; T15: evaluation after 15 days from the start of therapy; T-60: evaluation at the end of therapy.

\section{Discussion}

The present non-interventional study investigated the pharmacological efficacy of a fixed low-dose combination of cinnarizine $(20 \mathrm{mg})$ plus dimenhydrinate $(40 \mathrm{mg})$, as used under real-life conditions in the treatment of dizziness- and vertigo-related symptoms. The study population consisted of a representative sample of patients with vertigo, observed daily in our medical practice. Specifically, concerning age and sex, patients who attended this study represented a typical vertigo population: mostly male, with a mean age of 64 years $[46,47]$.

Although the complexity of the vestibular system and limited means make it difficult to establish an exact diagnosis, especially within the primary and secondary care settings, pharmacological management of patients with vertigo is of considerable importance, in particular for treating dizziness during the early acute phase of symptom onset $[38,48]$.

The common objective of pharmacological treatment is to inhibit vestibular sensory input and restore blood flow by improving the microcirculation [49,50]. A wide variety of drugs is used to treat vertigo and its associated symptoms, such as nausea and emesis. These medications may influence the response of neurons by facilitating or inhibiting the effect of the primary neurotransmitters, or by altering patterns of release and thereby modifying sensory transmission in the vestibular sensory pathways.

In agreement with previous studies conducted by Pytel [51], Scholtz [52], and others, the results of this study provide further insight regarding the efficacy of the aforementioned fixed low-dose combination when used to reduce vestibular vertigo symptoms of central and/or peripheral origin, as measured by the Dizziness Handicap Inventory and the Visual Scale of Dizziness Disorders, after both the 15-day therapy (primary evaluation of the efficacy of pharmacological therapy) and 60-day therapy (primary efficacy endpoint). In particular, independent of the type of vertigo, the fixed-combination treatment was able to reduce dizziness- and vertigo-associated symptoms in more than $75 \%$ of all patients treated, starting after 15 days of therapy, and improving 60 days after starting the therapy, to the end of observation.

In general, positive pharmacological effects obtained in our study could be attributable to different actions of the two active principles contained in the preparation employed, 
which work synergistically to reduce dizziness and other related symptoms. Cinnarizine, acting on the peripheral vestibular system, can selectively inhibit spasmogen-stimulated $\mathrm{Ca}^{2+}$ influx and promote an anti-vasoconstrictor action [53] that consequently causes an increase in blood flow to the vestibular nuclei. This activity counters the insufficient cerebral blood circulation likely responsible for "vertiginous symptoms" such as dizziness, nausea, vomiting, and tinnitus $[23,24,54,55]$. Furthermore, dimenhydrinate, through the block of $\mathrm{H} 1$ receptors abundantly located throughout the central vestibular nuclear complexincluding the medial vestibular nucleus-inhibits the spreading impulses at the medullar vestibular, which are closely associated with vegetative sensory regulation. This results in a decrease of the symptoms of vertigo and its associated vegetative complaints [7,56,57]. Thus, both active compounds act on structures embroiled in the pathogenesis of vertigo and associated vegetative symptoms.

In addition to evaluating the drugs' effects on the total number of patients treated, we wanted to investigate whether this medical compound was equally effective on both male and female patients. Interestingly, when the efficacy of the drug was evaluated on female patients, the combined action of the two active principles has proved to be useful in improving and reversing all vertigo symptoms, reaching higher efficacy 15 days after starting therapy. Only instability symptoms tend to decrease further after 60 days of therapy. In contrast, in male patients, we observed a greater reduction only in some of the symptoms analyzed. By the 15th day after the beginning of therapy, only staggeringand position-associated dizziness symptoms tended to revert, and we had to wait 60 days before observing a reduction in many of the other examined symptoms.

The difference in drug response between male and female patients observed in our study may be due to sex-based differences that impact pharmacokinetics. It has been reported that sex-related differences could induce changes in terms of the absorption, distribution, metabolism, and elimination of drugs. This can differentially affect their efficacy and safety, explaining why some drugs may function much better in females than in males, or vice versa. This could guide changes in dosage regimens or therapeutic monitoring, so as to increase the drugs' effectiveness or reduce potential toxicity [58,59]. Moreover, males and females are different in terms of physiology, and this can make a difference to the drugs' response.

Among physiological parameters, it seems that sex hormones play a determining role in the different pharmacokinetic responses between males and females. In particular, they exert a huge influence on the dose, plasma levels, interval of administration, and excretion, with significant clinical effects that are especially important for drugs with narrow therapeutic indexes [60]. Furthermore, increased levels of estrogen and progesterone can alter hepatic enzyme activity, which can increase drug accumulation or decrease the elimination of some drugs.

Hormonal levels that change during the menstrual cycle, with the use of oral contraceptives, throughout pregnancy, or during menopause, may affect the metabolism of drugs, thus modifying their action [61,62]. Sex hormones are prominent in the processes that underly the expression of the cytochrome P450 mono-oxygenases (CYP)450 system [60-65].

On the other hand, it has been established that gender-related differences in the gene expression of drug-metabolizing enzymes introduce alterations in drug metabolism, possibly affecting drug efficacy and safety $[66,67]$. Furthermore, the biochemical basis of sex differences in drug metabolism was also shown to be related to hormonal regulation of the production of drug-metabolizing enzymes in animals and humans $[68,69]$. Interindividual differences in drug metabolism are significantly influenced by polymorphisms in cytochrome P450 (CYP450). Variations in CYP450 activity may alter a drug's efficacy and/or lead to the onset of adverse effects. Cinnarizine, and to a lesser extent dimenhydrinate, are metabolized by CYP2D6, an enzymatic system that exhibits a high genetic polymorphism, whose activity appears to be higher in men than in women [70-72]. The higher expression of CYP2D6 in males than in females may, in part, explain our results. 
It is likely that the lower expression of CYP2D6 in females may promote a reduction in drug elimination and, consequently, increase the proportion of the administered drug that reaches the circulatory system. This potential increase might explain the increase in the drugs' therapeutic effects beginning from 15 days after the first administration more in female than in male patients.

Concerning the tolerability of the study treatment, we did not find any particular adverse effects reported in other studies. A low-dose fixed combination was well tolerated by both sexes, and the only frequently reported adverse effects were drowsiness, sedation, amnesia, and headache.

There are some limitations to this study that should be considered in future research. For example, due to the limited sample size, it is difficult to generalize about the different effects of a fixed combination of cinnarizine $(20 \mathrm{mg})$ and dimenhydrinate $(40 \mathrm{mg})$ between males and females. Furthermore, the absence of a control group did not allow us to determine the real efficacy of the drug under study.

Understanding the correlation between gender differences in drug response could contribute to the implementation of more effective intervention and prevention strategies in repressing different diseases.

\section{Conclusions}

In conclusion, the present study provides further details concerning the potential therapeutic efficacy of the fixed combination of cinnarizine and dimenhydrinate that, given three times daily, has proven to be an effective and well-tolerated treatment to counteract central, peripheral, and combined central/peripheral vertigo. Therefore, our results reinforce and add value to what has been previously reported regarding the efficacy and appropriateness of prescribing cinnarizine and dimenhydrinate in vertigo care.

Furthermore, our results suggest that these drugs could act in a gender-specific manner, paving the way for further research. Understanding differences in the symptoms of vertigo disorders using gender-based approaches could improve pharmacological treatment and the quality of medical care.

Author Contributions: Conceptualization and management, F.M.; has formulated evolution of overarching research goals and aims, coordinated the research activity planning and execution, and acquired the financial support project leading to this publication. Investigation, P.S., F.D. and G.M.; these authors have carried out research and investigation activity, specifically performing the experiments, or data/evidence collection. Formal analysis: F.P. and E.C.; they have provided statistical, mathematical, computational, or other formal techniques to analyze or synthesize study data. Furthermore, F.P. All authors have read and agreed to the published version of the manuscript.

Funding: This research was supported by a grant from ALASI.

Institutional Review Board Statement: The study was conducted according to the guidelines of the Declaration of Helsinki, and approved by the Ethics Committee of the AOUP "P. Giaccone" (protocol code 38/03, date of approval: $10 / 12 / 19)$.

Informed Consent Statement: Written informed consent has been obtained from the patient(s) to publish this paper.

Data Availability Statement: The data is not publicly available due to privacy restrictions.

Conflicts of Interest: The authors declare no conflict of interest.

\section{References}

1. Karatas, M. Central vertigo and dizziness: Epidemiology, differential diagnosis, and common causes. Neurologist 2008, 14, 355-364. [CrossRef]

2. Watkins, J.C.; Evans, R.H. Excitatory amino acid transmitters. Ann. Rev. Pharmacol. Toxicol. 1981, 21, 165-204. [CrossRef]

3. Hilding, D.; Wersäll, J. Cholinesterase and its relation to the nerve endings in the inner ear. Acta Otolaryngol. 1962, 55, $205-217$. [CrossRef]

4. Guth, P.S.; Perin, P.; Norris, C.H.; Valli, P. The vestibular hair cells: Post-transductional signal processing. Prog. Neurobiol. 1998, 54, 193-247. [CrossRef] 
5. Cirek, Z.; Schwarz, M.; Baumann, W.; Novotny, M. Efficacy and Tolerability of a FixedCombination of Cinnarizine and Dimenhydrinate versus Betahistine in the Treatment of Otogenic Vertigo: A Double-Blind, Randomised Clinical Study. Clin. Drug. Investig. 2005, 25, 377-389. [CrossRef]

6. Highstein, S.M.; Holstein, G.R. The anatomy of the vestibular nuclei. Prog. Brain Res. 2006, 151, 157-203. [CrossRef]

7. Soto, E.; Vega, R.; Seseña, E. Neuropharmacological basis of vestibular system disorder treatment. J. Vestib. Res. 2013, 23, 119-137. [CrossRef]

8. Neuhauser, H.K. The epidemiology of dizziness and vertigo. Handb. Clin. Neurol. 2016, 137, 67-82. [CrossRef]

9. Bronstein, A.M. Vision and vertigo: Some visual aspects of vestibular disorders. J Neurol. 2004, 251, 381-387. [CrossRef] [PubMed]

10. Sloan, P.D. Dizziness in primary care. Results from the national ambulatory medical care survey. J. Fam. Pract. 1989, $29,33-38$.

11. Mira, E. Improving the quality of life in patients with vestibular disorders: The role of medical treatments and physical rehabilitation. Int. J. Clin. Pract. 2008, 62, 109-114. [CrossRef]

12. Jönsson, R.; Sixt, E.; Landahl, S.; Rosenhall, U. Prevalence of dizziness and vertigo in an urban elderly population. J. Vestib. Res. 2004, 14, 47-52. [PubMed]

13. Magnusson, M.; Karlberg, M. Peripheral vestibular disorders with acute onset of vertigo. Curr. Opin. Neurol. 2002, 15, 5-10. [CrossRef] [PubMed]

14. Kerber, K.A.; Baloh, R.W. The evaluation of a patient with dizziness. Neurol. Clin. Pract. 2011, 1, 24-33. [CrossRef]

15. Post, R.E.; Dickerson, L.M. Dizziness: A diagnostic approach. Am. Fam. Physician 2010, 82, 361-369.

16. Smith, D.B. Dizziness: The history and physical examination. In Dizziness and Balance Disorders: An Interdisciplinary Approach to Diagnosis, Treatment, and Rehabilitation; Arenberg, I.K., Ed.; Kugler Pubblications: Amstrerdam, The Netherlands; New York, NY, USA, 1993; pp. 3-10.

17. Brandt, T. Vertigo: Its Multisensory Syndromes, 2nd ed.; Springer: Berlin/Heidelberg, Germany; New York, NY, USA, 1999.

18. Luxon, L.M.; Bamiou, D.E. Vestibular System Disorder. In Neurology and Clinical Neuroscience; Schapira, A.H.V., Ed.; Mosby, Elsevier: Maryland Heights, MO, USA, 2006; pp. 337-352.

19. Hamid, M.A. Overview of clinical anatomy and physiology of the vestibular system. In Dizziness and Balance Disorders; Arenberg, I.K., Ed.; Kugler Pubblications: Amsterdam, The Netherlands, 1993; pp. 41-43.

20. Yoo, H.; Mihaila, D.M. Neuroanatomy, Vestibular Pathways. In StatPearls [Internet]; StatPearls Publishing: Treasure Island, FL, USA, 2020.

21. Baloh, R.W.; Honrubia, V. Clinical Neurophysiology of the Vestibular System, 3rd ed.; Oxford University press: Oxord, UK, 2001.

22. Honrubia, V.; House, M. Mechanism of posterior semicircular canal stimulation in patients with benign paroxysmal positional vertigo. Acta Otolaryngol. 2001, 121, 234-240. [CrossRef] [PubMed]

23. Cavallaro, A.; Martines, F.; Cannizzaro, C.; Lavanco, G.; Brancato, A.; Carollo, G.; Plescia, F.; Salvago, P.; Cannizzaro, E.; Mucia, M.; et al. Role of Cannabinoids In The Treatment of Tinnitus. Acta Med. Mediterr. 2016, 32, 903-909.

24. Plescia, F.; Cannizzaro, C.; Brancato, A.; Federico, S.; Salvago, P.; Martines, F. Emerging Pharmacological Treatments of Tinnitus. Tinnitus: Epidemiology, Causes and Emerging Therapeutic Treatments, 1st ed.; Watson, J., Ed.; Nova Science Publishers, Inc.: New York, NY, USA, 2016; pp. 43-64. ISBN1 978-163484155-9. ISBN2 978-163484154-2.

25. Udagatti, V.D.; Dinesh Kumar, R. Migraine Related Vertigo. Indian J. Otolaryngol. Head Neck Surg. 2017, 69, 563-567. [CrossRef]

26. Cronin, T.; Arshad, Q.; Seemungal, B.M. Vestibular Deficits in Neurodegenerative Disorders: Balance, Dizziness, and Spatial Disorientation. Front. Neurol. 2017, 26, 538. [CrossRef]

27. Luxon, L.M. Evaluation and management of the dizzy patient. JNNP 2004, 75, 45-52. [CrossRef]

28. Brandt, T.; Dieterich, M.; Strupp, M. Vertigo and Dizziness: Common Complaints, 2nd ed.; Springer: London, UK, 2013 ; pp. 1-184.

29. Oosterveld, W.J. Vertigo. Current concepts in management. Drugs 1985, 30, 275-283. [CrossRef] [PubMed]

30. Darlington, C.L.; Smith, P.F. Drug treatment for vertigo and dizziness. N. Z. Med. J. 1998, 111, 332-334. [PubMed]

31. Lee, C.; Jones, T.A. Neuropharmacological Targets for Drug Action in Vestibular Sensory Pathways. J. Audiol. Otol. 2017, 21, 125-132. [CrossRef] [PubMed]

32. Otto, V.; Fischer, B.; Schwarz, M.; Baumann, W.; Preibisch-Effenberger, R. Treatment of vertebrobasilar insufficiency-associated vertigo with a fixed combination of cinnarizine and dimenhydrinate. Int. Tinnitus J. 2008, 14, 57-67. [PubMed]

33. Oosterveld, W.J. The effectiveness of piracetam in vertigo. Pharmacopsychiatry 1999, 32, 54-60. [CrossRef] [PubMed]

34. Emanuel, M.B.; Will, J.A. Cinnarizine in the treatment of peripheral vascular disease: Mechanisms related to its clinical action. Proc. R. Soc. Med. 1977, 70, 7-12. [CrossRef]

35. Arab, S.F.; Düwel, P.; Jüngling, E.; Westhofen, M.; Lückhoff, A. Inhi-bition of voltage-gated calcium currents in type II vestibular hair cells by cinnarizine. Naunyn Schmiedeberg's Arch. Pharmacol. 2004, 369, 570-575. [CrossRef]

36. Yoo, M.H.; Yang, C.J.; Kim, S.A.; Park, M.J.; Ahn, J.H.; Chung, J.W.; Park, H.J. Efficacy of steroid therapy based on symptomatic and functional improvement in patients with vestibular neuritis: A prospective randomized controlled trial. Eur. Arch. Otorhinolaryngol. 2017, 274, 2443-2451. [CrossRef]

37. Lepcha, A.; Amalanathan, S.; Augustine, A.M.; Tyagi, A.K.; Balraj, A. Flunarizine in the prophylaxis of migrainous vertigo: A randomized controlled trial. Eur. Arch. Otorhinolaryngol. 2014, 271, 2931-2936. [CrossRef]

38. Hain, T.C.; Uddin, M. Pharmacological treatment of vertigo. CNS Drugs 2003, 17, 85-100. [CrossRef] [PubMed]

39. Almanza, A.; Navarrete, F.; Vega, R.; Soto, E. Modulation of voltage-gated Ca2+ current in vestibular hair cells by nitric oxide. J. Neurophysiol. 2007, 97, 1188-1195. [CrossRef] [PubMed] 
40. Oosterveld, W.J. Cinnarizine in the vertiginous syndrome. In Cinnarizine and the Vertiginous Syndrome; Towse, G., Ed.; International Congress and Symposium Series No. 33; Royal Society of Medicine and Academic Press Inc.: London, UK, 1999 ; pp. $29-37$.

41. Godfraind, T.; Towse, G.; Van Nueten, J.M. Cinnarizine: A selective calcium entry blocker. Drugs Today 1982, 18, $27-42$.

42. Kirtane, M.V.; Bhandari, A.; Narang, P.; Santani, R. Cinnarizine: A Contemporary Review. Indian J. Otolaryngol. Head Neck. Surg. 2019, 71, 1060-1068. [CrossRef] [PubMed]

43. Hausler, R.; Sabani, E.; Rohr, M. L'effet de la Cinnarizine sur divers types de vertiges. Résultats cliniques et électronystagmographiques d'une étude en double aveugle [Effect of cinnarizine on various types of vertigo. Clinical and electronystagmographic results of a double-blind study]. Acta Otorhinolaryngol. Belg. 1989, 43, 177-185. [PubMed]

44. Khilnani, A.K.; Thaddanee, R.; Khilnani, G. Anti vertigo Drugs-Revisited. NJIRM 2013, 4, 118-128.

45. Huppert, D.; Strupp, M.; Mückter, H.; Brandt, T. Which medication do I need to manage dizzy patients? Acta Otolaryngol. 2011, 131, 228-241. [CrossRef]

46. Penger, M.; Strobl, R.; Grill, E. Country-specific and individual determinants of dizziness in Europe: Results from the Survey of Health Ageing and Retirement in Europe (SHARE). Public Health 2017, 149, 1-10. [CrossRef]

47. Neuhauser, H.K.; Radtke, A.; von Brevern, M.; Lezius, F.; Feldmann, M.; Lempert, T. Burden of dizziness and vertigo in the community. Arch. Intern. Med. 2008, 168, 2118-2124, Erratum in 2009, 169, 89. [CrossRef]

48. Baloh, R.W. Clinical practice. Vestibular neuritis. N. Engl. J. Med. 2003, 348, 1027-1032. [CrossRef]

49. Claes, J.; Van de Heyning, P.H. A review of medical treatment for Ménière's disease. Acta. Otolaryngol. Suppl. 2000, 544, 34-39. [CrossRef]

50. Walther, L.E. Procedures for restoring vestibular disorders. GMS Curr. Top Otorhinolaryngol. Head Neck Surg. 2005, 4, Doc5.

51. Pytel, J.; Nagy, G.; Toth, A.; Spellenberg, S.; Schwarz, M.; Repassy, G. Efficacy and tolerability of a fixed low-dose combination of cinnarizine and dimenhydrinate in the treatment of vertigo: A 4-week, randomized, double-blind, active- and placebo-controlled, parallel-group, outpatient study. Clin. Ther. 2006, 29, 84-98. [CrossRef] [PubMed]

52. Scholtz, A.W.; Ligner, J.; Loader, B.; Pritschow, B.W.; Weisshaar, G. Cinnarizine and dimenhydrinate in the treatment of vertigo in medical practice. Wien. Klin. Wochenschr. 2016, 128, 341-347. [CrossRef] [PubMed]

53. Labugen, R.H. Initial evaluation of vertigo. Am. Fam. Physician 2006, 73, 244-251.

54. Dispenza, F.; Mazzucco, W.; Mazzola, S.; Martines, F. Observational study on risk factors determining residual dizziness after successful benign paroxysmal positional vertigo treatment: The role of subclinical BPPV. Acta Otorhinolaryngol. Italica 2019, 39, 347-352. [CrossRef] [PubMed]

55. Swartz, R.; Longwell, P. Treatment of vertigo. Am. Fam. Physician 2005, 71, 1115-1122.

56. Dyhrfjeld-Johnsen, J.; Attali, P. Management of peripheral vertigo with antihistamines: New options on the horizon. Br. J. Clin. Pharmacol. 2019, 85, 2255-2263. [CrossRef]

57. Chen, Z.P.; Zhang, X.Y.; Peng, S.Y.; Yang, Z.Q.; Wang, Y.B.; Zhang, Y.X.; Chen, X.; Wang, J.J.; Zhu, J.N. Histamine H1 Receptor Contributes to Vestibular Compensation. J. Neurosci. 2019, 39, 420-433. [CrossRef]

58. Farkouh, A.; Riedl, T.; Gottardi, R.; Czejka, M.; Kautzky-Willer, A. Sex-Related Differences in Pharmacokinetics and Pharmacodynamics of Frequently Prescribed Drugs: A Review of the Literature. Adv. Ther. 2020, 37, 644-655. [CrossRef]

59. Beierle, I.; Meibohm, B.; Derendorf, H. Gender differences in pharmacokinetics and pharmacodynamics. Int. J. Clin. Pharmacol. Ther. 1999, 37, 529-547.

60. Soldin, O.P.; Mattison, D.R. Sex differences in pharmacokinetics and pharmacodynamics. Clin. Pharmacokinet. 2009, 48, 143-157. [CrossRef]

61. Ostrom, N.K. Women with asthma: A review of potential variables and preferred medical management. Ann. Allergy Asthma Immunol. 2006, 96, 655-665. [CrossRef]

62. Miller, A.A.; De Silva, T.M.; Jackman, K.A.; Sobey, C.G. Effect of gender and sex hormones on vascular oxidative stress. Clin. Exp. Pharmacol. Physiol. 2007, 34, 1037-1043. [CrossRef] [PubMed]

63. Franconi, F.; Carru, C.; Malorni, W.; Vella, S.; Mercuro, G. The effect of sex/gender on cardiovascular pharmacology. Curr. Pharm. Des. 2011, 17, 1095-1107. [CrossRef]

64. Jochmann, N.; Stangl, K.; Garbe, E.; Baumann, G.; Stangl, V. Female-specific aspects in the pharmacotherapy of chronic cardiovascular diseases. Eur. Heart J. 2005, 26, 1585-1595. [CrossRef]

65. Oertelt-Prigione, S.; Regitz-Zagrosek, V. Gender aspects in cardiovascular pharmacology. J. Cardiovasc. Transl. Res. 2009, 2, 258-266. [CrossRef] [PubMed]

66. Kato, R. Sex-related differences in drug metabolism. Drug. Metab. Rev. 1974, 3, 1-32. [CrossRef]

67. Wizemann, T.M.; Pardue, M.L. Exploring the Biological Contributions to Human Health: Does Sex Matter? National Academies: Washington, DC, USA, 2001; ISBN-10: 0-309-07281-6.

68. Yang, L.; Li, Y.; Hong, H.; Chang, C.W.; Guo, L.W.; Lyn-Cook, B.; Shi, L.; Ning, B. Sex Differences in the Expression of Drug-Metabolizing and Transporter Genes in Human Liver. J. Drug Metab. Toxicol. 2012, 3, 1000119. [CrossRef] [PubMed]

69. Waxman, D.J.; Holloway, M.G. Sex differences in the expression of hepatic drug metabolizing enzymes. Mol. Pharmacol. 2009, 76, 215-228. [CrossRef]

70. Narimatsu, S.; Kariya, S.; Isozaki, S.; Ohmori, S.; Kitada, M.; Hosokawa, S.; Masubuchi, Y.; Suzuki, T. Involvement of CYP2D6 in oxidative metabolism of cinnarizine and flunarizine in human liver microsomes. Biochem. Biophys. Res. Commun. 1993, 193, 1262-1268. [CrossRef] 
71. Thuerauf, N.; Lunkenheimer, J. The impact of the CYP2D6-polymorphism on dose recommendations for current antidepressants. Eur. Arch. Psychiatry Clin. Neurosci. 2006, 256, 287-293. [CrossRef] [PubMed]

72. Tanaka, E. Gender-related differences in pharmacokinetics and their clinical significance. J. Clin. Pharm. Ther. 1999, 24, 339-346. [CrossRef] [PubMed] 